\title{
Influence of process parameters on mechanical properties of friction stir welded 5083-O aluminum alloy
}

\author{
Nicole Brum ${ }^{1}$ \\ Carla Amavisca ${ }^{1}$ \\ Jerônimo Ghisi Schroeder ${ }^{1}$ \\ Jonas Buzzatti ${ }^{i}$ \\ Guilherme Vieira Braga Lemos ${ }^{1}$ (1) \\ Diego Tolotti ${ }^{2}$ \\ Marcelo Favaro ${ }^{1}$
}

\begin{abstract}
Friction Stir Welding (FSW) is a solid-state joining process that has been demonstrating to be an excellent alternative for joining aluminum alloys. Therefore, this work presents the influence of process parameters (rotational speed, welding speed, and tool shoulder penetration) on mechanical properties of friction-stir-welded AA 5083-O. The welded joints were analyzed by metallography, tensile, and bending tests. Furthermore, the surface fracture of the best joint was evaluated by scanning electron microscopy (SEM) for verifying the major fracture mechanism. It was found that the ultimate tensile strength (UTS) of the welds was similar to that of the base material. Moreover, the microhardness profiles were comparable along the regions considered. Also, the failures of both bending and tensile tests tend to occur on the advancing side.
\end{abstract}

Keywords: Friction stir welding; AA 5083-O; Process parameters; Mechanical properties.

\section{Introduction}

In several applications, the use of aluminum alloys has grown over the years. The advantages of using aluminum for replacing steel are related to high strength-weight relation, which allows the increase of transports carrying capacity or less fuel consumption and, therefore, less $\mathrm{CO}_{2}$ emission [1]. Among the several alloys available, the 5083-O alloy is widely employed in the automotive, aerospace, and naval industries due to its corrosion resistance, mechanical properties, and low density [2]. Besides, the aluminum alloys of $5 \mathrm{xxx}$ series are considered not hardenable by heat treatment [3].

Welding of aluminum alloys may be challenging due to their properties, such as high thermal conductivity and coefficient of thermal expansion. As a consequence, the formation of porosities and cracks is typical in fusion welding of aluminum alloys. Thus, manufacturing processes with low heat input, as friction-based welding, are recommended for these alloys [4]. Friction stir welding (FSW) is a solidstate joining process that can provide high-quality joints. Moreover, its lower heat input may reduce microstructural changes, preventing precipitate coarsening and dissolution, and still result in microstructure recrystallization [5]. In this context, FSW is currently being used in various industrial applications, such as naval, automotive, aerospace industry, and also high-speed train manufacturing [6-8]. FSW uses a non-consumable tool with a probe for joining join two workpieces. The rotating tool and its transversal speed promote the material's mixing in the hot plasticized state to produce the sound joint [5]. Improved joint quality is one of the main advantages since FSW usually does not involve materials melting. Furthermore, FSW is considered a "green" technology due to its efficiency and less consumable energy $[9,10]$.

Many authors studied friction stir welds of AA 5083 and the process parameters influence on their joint properties. Mishra and Rani [11] found that tool rotational speed is the most significant for decreasing the elongation of the joints. Klobcar [12] reported that the weld with excessive flash generation, grain growth, and lower hardness than the base material occurs due to high frictional heat input. Rao et al. [13] studied the asymmetric distribution of microstructure and mechanical properties. It was found that the hardness sharply decreased from the HAZ to the stir zone (SZ) (on the advancing side (AS)), and this gradient is small on the RS. Prabha et al. [14] investigated the effects of tool rotational speeds of $900 \mathrm{rpm}, 1120 \mathrm{rpm}, 1400 \mathrm{rpm}, 1800 \mathrm{rpm}$ at a welding speed of $40 \mathrm{~mm} / \mathrm{min}$. The best ultimate tensile

\footnotetext{
${ }^{1}$ Laboratório de Metalurgia Física - LAMEF, Programa de Pós-graduação em Engenharia de Minas, Metalúrgica e de Materiais - PPGE3M, Universidade Federal do Rio Grande do Sul-UFRGS, Porto Alegre, RS, Brasil.

${ }^{2}$ Bruning Tecnometal, Panambi, RS, Brasil.

Corresponding author: nicole.brum@gmail.com
}

2176-1523 C 2021. Brum et al. Published by ABM. This is an Open Access article distributed under the terms of the Creative Commons Attribution License, which permits unrestricted use, distribution, and reproduction in any medium, provided the original work is properly cited. 
strength (UTS) and finer microstructure were obtained at a tool rotational speed of $1120 \mathrm{rpm}$. Hirata et al. [15] verified different tool rotational and transverse speeds and found that at various conditions, the microstructures of the stir zones consisted of fine equiaxed grains. The hardness in the SZ increased with the decrease in friction heat flow and grain size. Also, the UTS under each FSW condition was almost the same, and the formability in FS-welded $5083 \mathrm{Al}$ alloy was improved by decreasing the friction heat flow.

The current work focuses on FSW for joining AA 5083-O plates, aiming at an optimization of the process parameters and evaluation of the processed joints. Hence, the Box-Behnken methodology was applied to investigate the effects of rotational speed, transverse speed, and shoulder penetration on the joint properties. Furthermore, scanning electron microscopy (SEM) was used for verifying the dominant fracture mechanism.

\section{Materials and methods}

The base material used in this work was an aluminum 5083-O alloy with 400 x 80 × $6.35 \mathrm{~mm}$. The welding tool, made of AISI H13 steel, had a shoulder with an $18 \mathrm{~mm}$ diameter and a conical probe of $6 \mathrm{~mm}$ length. Furthermore, the tool geometry is shown in Figure 1a and $1 b$.

Friction stir welds were produced by a machine made for FSW, shown in Figure 1c, which has $70 \mathrm{kN}$ axial force capacity, rotational speed up to $4000 \mathrm{rpm}$, and maximum transverse speed of $2000 \mathrm{~mm} / \mathrm{min}$.

Three-factor three levels Box-Behnken matrix in response surface methodology was employed to the experimental investigation (as used in [17]). The parameters investigated were: rotational speed (rpm) 1100, 1200 and 1300 , transverse speed $(\mathrm{mm} / \mathrm{min}) 25,30$ and 35 , and shoulder penetration $(\mathrm{mm}) 0.10,0.15$ and 0.20 . The joints were processed with $2.5^{\circ}$ tool tilt angle and dwell time of 30 seconds. Table 1 shows the joints (identified by numbers) and the experiments considered. Hence, a total of fifteen welds was produced.

The samples were prepared according to the basic metallography practices and etched by Keller (distilled water, nitric acid, hydrochloric acid, and hydrofluoric acid) to macroscopic analysis. This procedure was performed in the joints without defects in the surface (all the joints except $\# 2$, \#3, and \#9).

The root bend tests were undertaken as per ISO 25239-4 standard [18]. The bend test was carried out in the joints without voids or porosities (welds \#6, \#10, \#11, \#12, \#13, and \#15).

The tensile tests were done as suggested by the ASTM E8 standard [19] on an Instron machine with $250 \mathrm{kN}$ capacity (Model $5585 \mathrm{H}$ ). The specimens were machined with a $50 \mathrm{~mm}$ gauge length and stirred zone positioned in the middle of the sample length. Also, the tensile tests were done in the approved samples of the bending tests (\#6, \#10,\#11, and \#13).
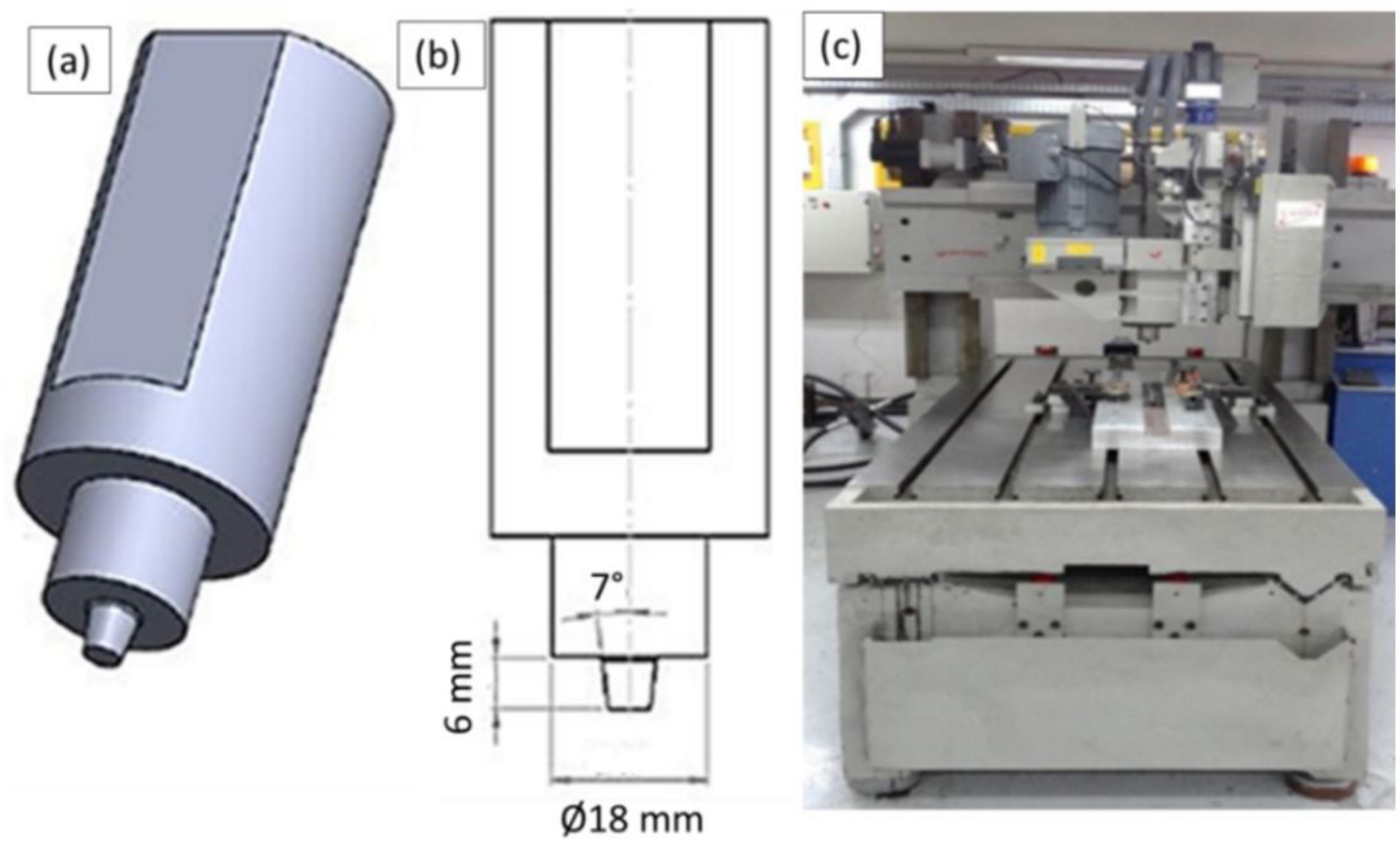

Figure 1. (a), (b) Schematic drawn of the tool geometry [16], and (c) Friction stir welding. 
Further, based on the average ultimate tensile strength (UTS) and yield strength (YS), the best joint (\#13) was chosen, and its fracture surface was investigated by scanning electron microscopy (SEM).

Microhardness and metallographic analyses were carried out in the best joint (chosen based on previous results). Therefore, Vickers microhardness was measured in weld \#13 (at $2.1 \mathrm{~mm}$ and $4.2 \mathrm{~mm}$ distance from the top surface).

\section{Results and discussion}

\subsection{Top surface appearance}

Figure 2 shows the top surface appearance of the joints. As can be observed, the welds $\# 2, \# 3$, and $\# 9$ presented a surface groove, and thus they were not approved for the subsequent analyses. The visual assessment recognized

Table 1. Box-Behnken design according to process parameters

\begin{tabular}{cccc}
\hline Weld & Rotational Speed $[\mathbf{r p m}]$ & Transverse Speed $[\mathbf{m m} / \mathbf{m i n}]$ & Shoulder Penetration $[\mathbf{m m}]$ \\
\hline$\# 1$ & 1200 & 30 & 0.15 \\
$\# 2$ & 1100 & 30 & 0.10 \\
$\# 3$ & 1200 & 30 & 0.15 \\
$\# 4$ & 1300 & 25 & 0.15 \\
$\# 5$ & 1100 & 35 & 0.15 \\
$\# 6$ & 1300 & 30 & 0.20 \\
$\# 7$ & 1300 & 35 & 0.15 \\
$\# 8$ & 1200 & 35 & 0.10 \\
$\# 9$ & 30 & 0.15 \\
$\# 10$ & 1200 & 35 & 0.20 \\
$\# 11$ & 1200 & 25 & 0.20 \\
$\# 12$ & 1200 & 30 & 0.10 \\
$\# 13$ & 1300 & 30 & 0.20 \\
$\# 15$ & 1100 & 25 & 0.15 \\
& 1100 & 25 & 0.10 \\
\hline
\end{tabular}

1

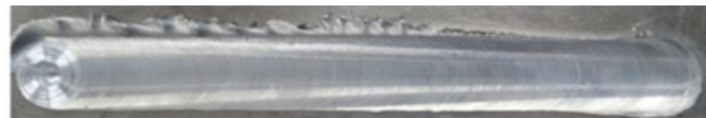

2

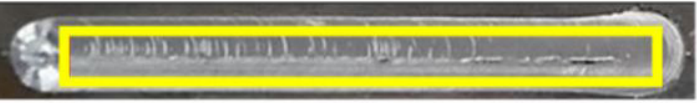

3

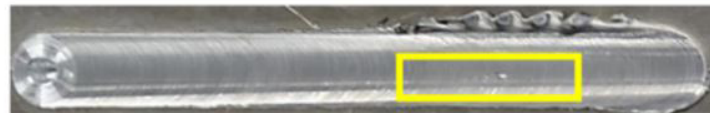

4

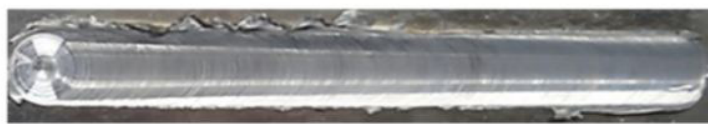

5

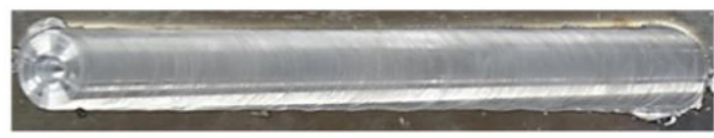

6

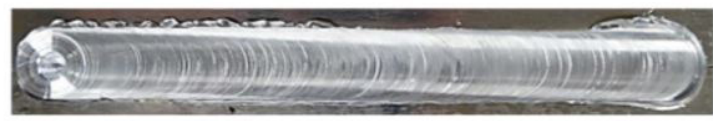

7

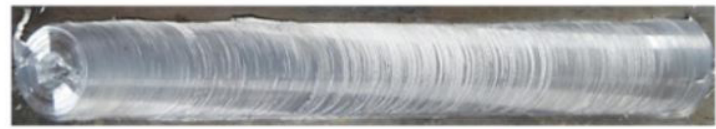

8

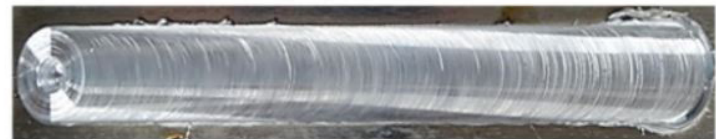

9

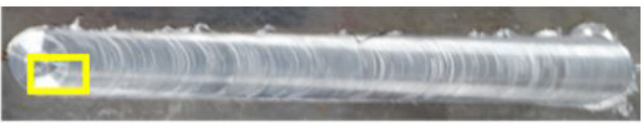

10

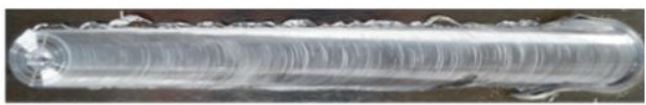

11

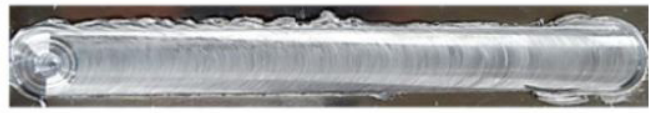

12

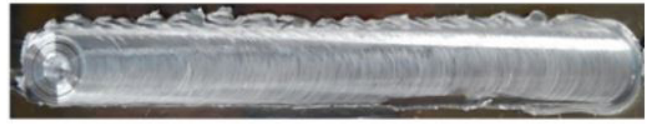

13

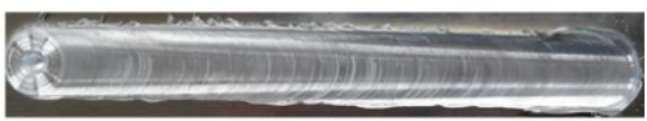

14

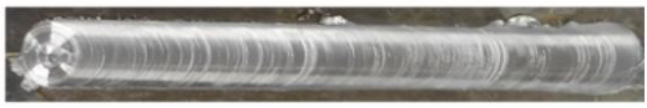

15

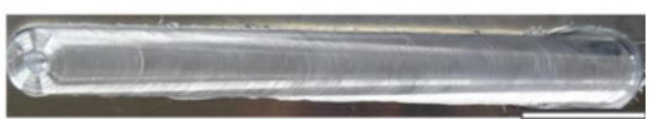

$30 \mathrm{~mm}$

Figure 2. Top surface appearance of the welds evidencing surface groove defect in the rectangle. 
that the sharp flash tends to occur on the retreating side (RS). Kim et al. [20] described this fact is due to the metal softening occasioned by the excessive heat input during FSW. Keivani et al. [21] reported that at high tool tilt angles, insufficient plasticized material remains to fill the cavity left in the weld nugget, and weld flash appears on the retreating side [22]. Indeed, the joints with sharp flash (current work) were processed by higher rotational speeds (1200 and $1300 \mathrm{rpm}$ ).

\subsection{Macrostructure}

In Figure 3, the macrostructures show the severe plastic deformation (SPD) caused by the tool movement and material mixing during FSW. It can also be observed the typical zones as SZ and onion rings.

Six of the joints (\#1, \#4, \#5, \#7, \#8, and \#14), although they had good surface quality, presented porosities or voids in the macrographs (indicating by narrows in Figure 3). In general, the voids were located on the advancing side. This defect can be developed by abnormal stirring, which is due to the different temperatures between the upper part (near the surface) and the lower [20]. Also, this defect size increases with improvement in the transverse speed [23]. Another reason for void formation could be microstructural changes that tend to be more heterogeneous on that side [24]. The local void is called by Chen et al. [25] as the triple junction of the shoulder flow zone, indicating a terminating flow in this zone. Still, Chen et al. [25] mentioned that this defect is a result of slightly insufficient shoulder flow.

\subsection{Bending tests}

As can be observed in Figure 4, the joints \#12 and \#15 showed cracks in the weld zone. Also, the joints \#6, $\# 10$, \#11, and \#13 reached a bent root angle of around $150^{\circ}$ without any cracking. The joints that did not present any defects (\#6, \#10,\#11, and \#13) were produced with different rotational and transverse speeds (Table 1) and maximum shoulder penetration $(0.20 \mathrm{~mm})$, indicating that the penetration is also important to the quality of the welds.

\subsection{Tensile testing}

The joints (\#6,\#10,\#11, and \#13) did not show any defects in bending tests. Therefore, they were selected for tensile testing. Figure 5 shows the average yield strength (YS), ultimate tensile strength (UTS), and elongation. It was verified that the YS reached by the joints was around $85 \%$ of the base material. Moreover, the UTS and elongation of the welds were comparable to the base material. Still, the rupture occurred in the weld region (Figure 6). Finally, joint \#13 was selected as the best weld due to its average UTS and YS. These mechanical properties results are in good agreement with related studies on FSW of aluminum alloys, where the YS and UTS were 145 and $259 \mathrm{MPa}$, respectively [26].

\subsection{Microstructure and microhardness}

In Figure 7, the microstructural features of joint \#13 are shown. It can be seen that the joint is free of cracks or porosities, consequently indicating its suitable quality. In
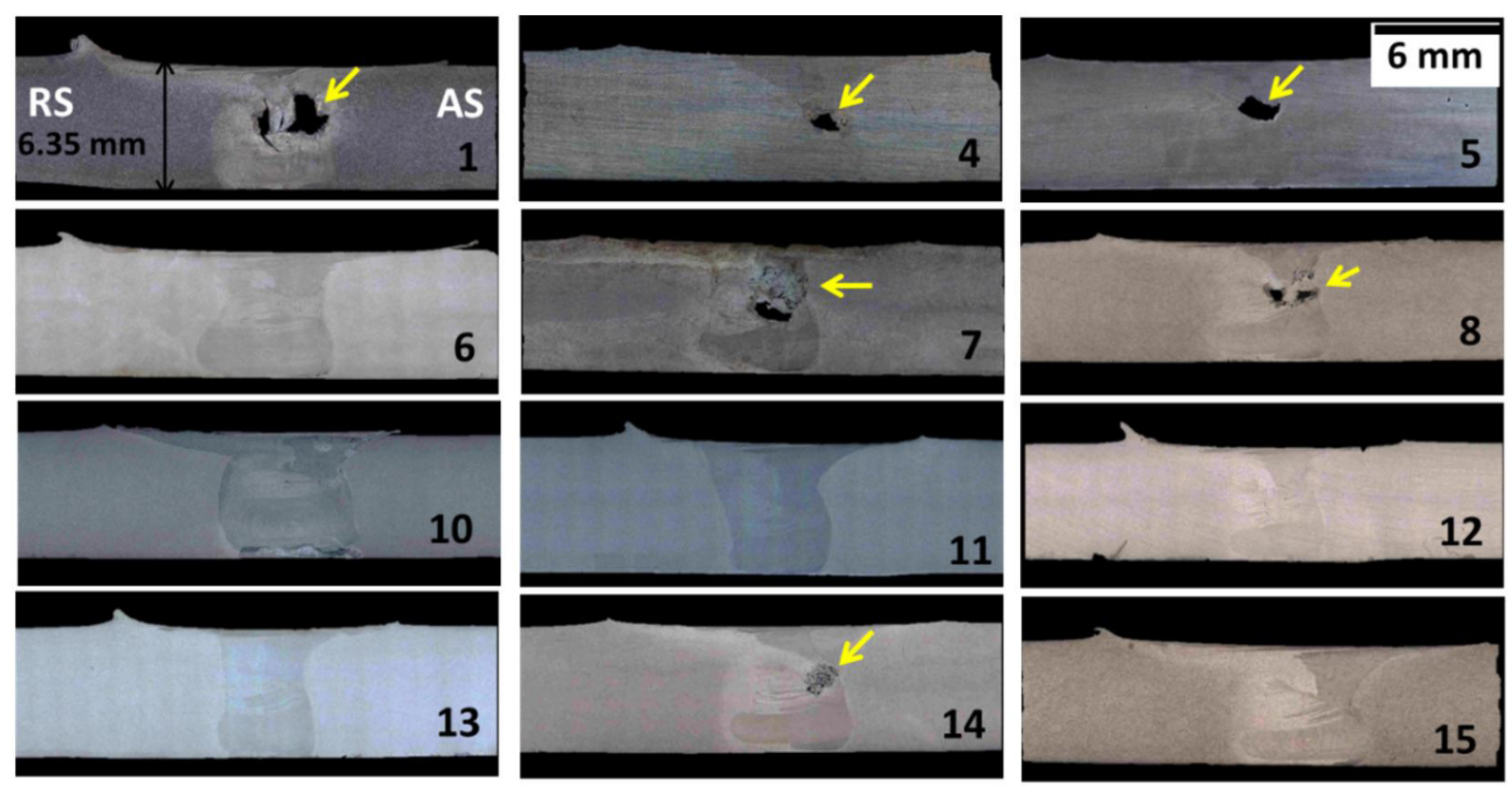

Figure 3. Macrostructure of the joints, retreating side (RS) and advancing side (AS) the arrows indicate the void defect. 

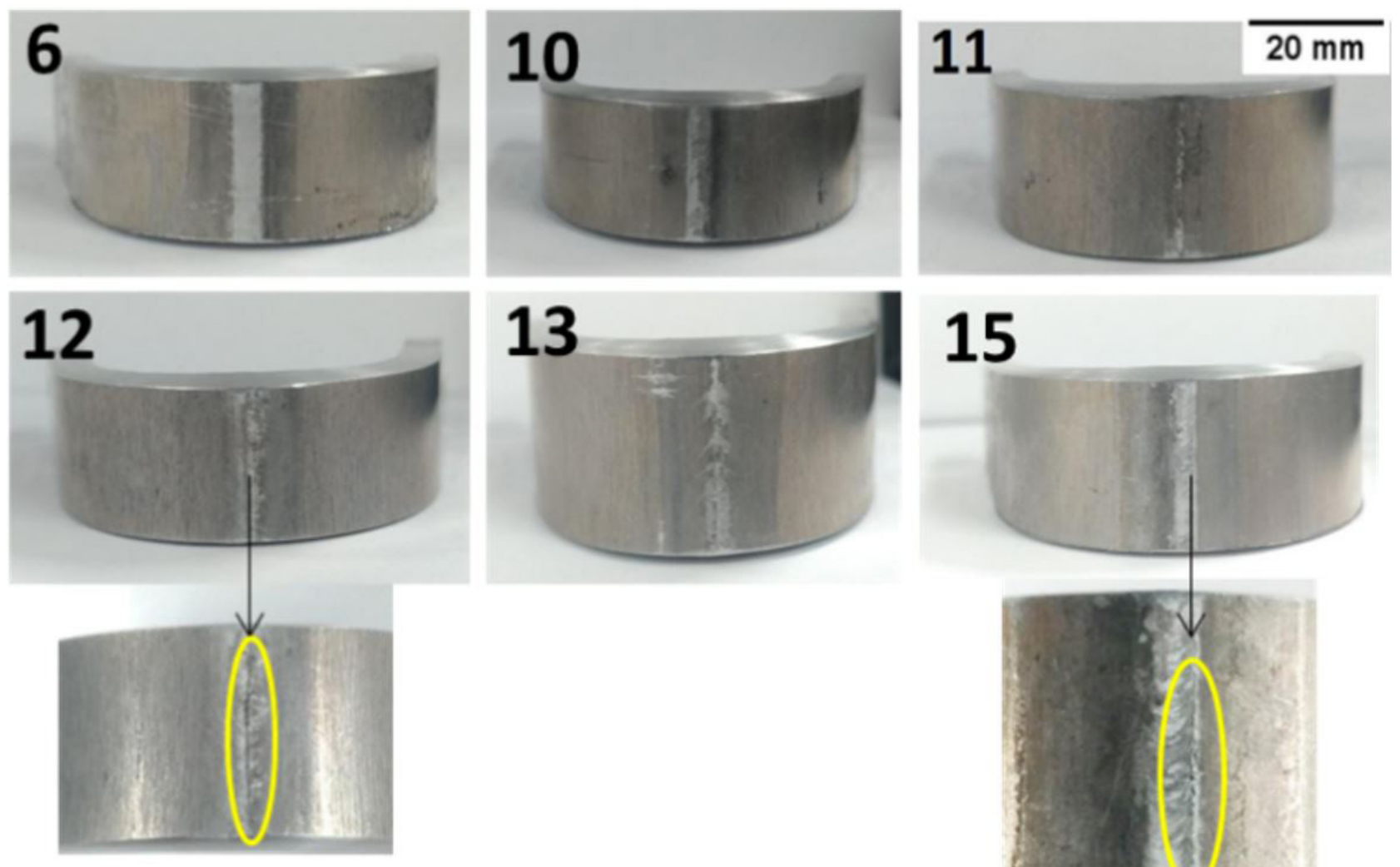

\section{5}

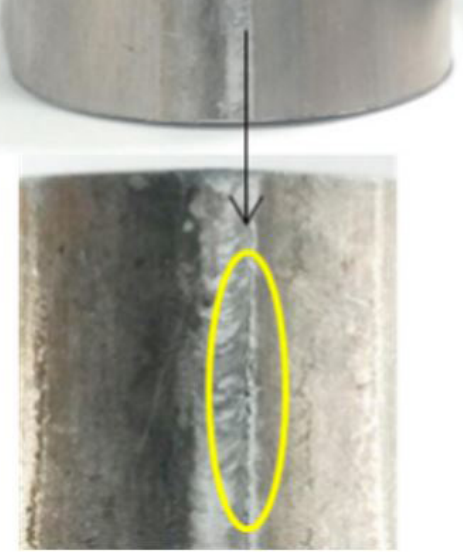

Figure 4. Welded joints after bending tests evidecing cracks in the circle.

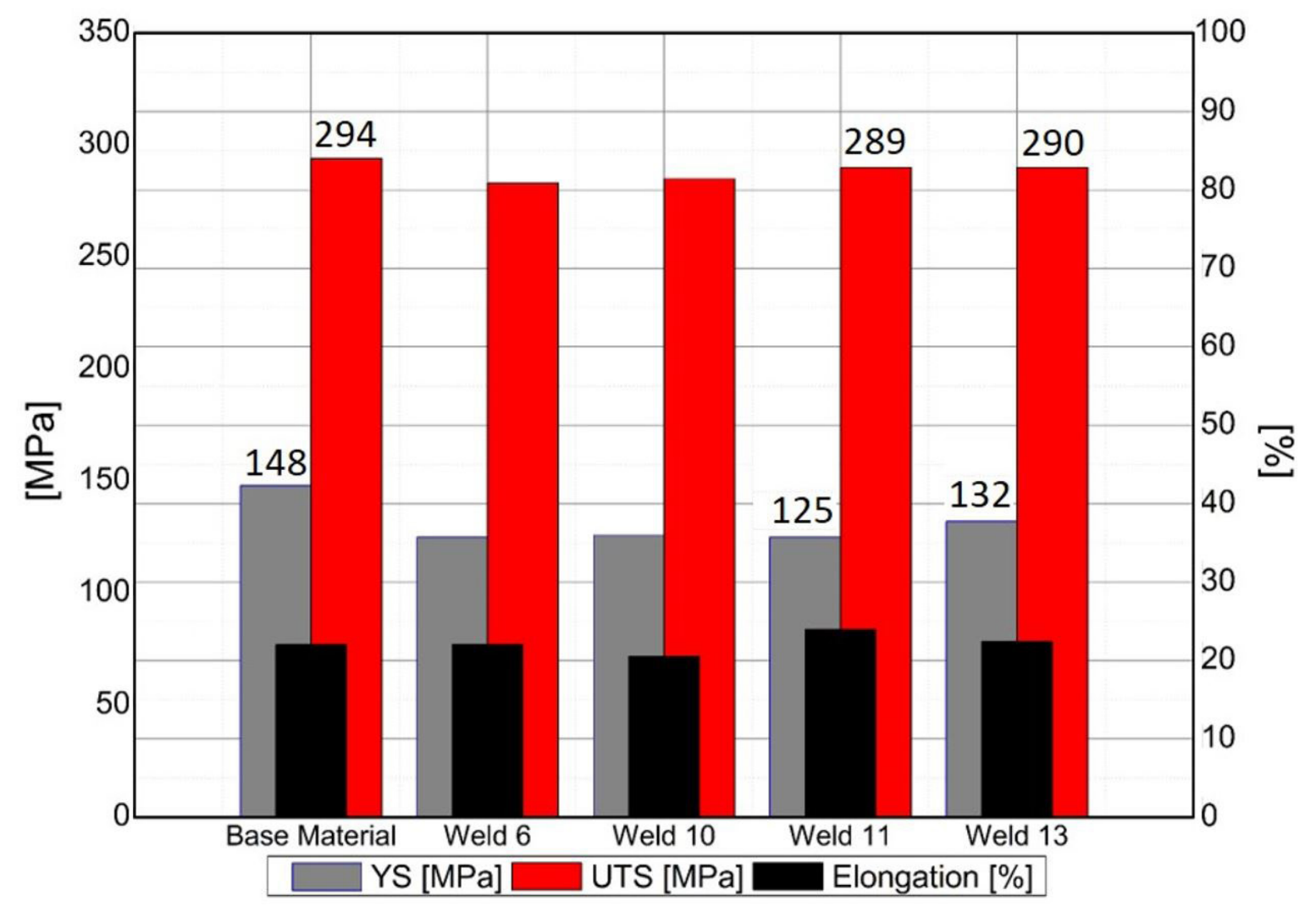

Figure 5. Average mechanical properties for the base material and joints \#6, \#10, \#11, and \#13. 


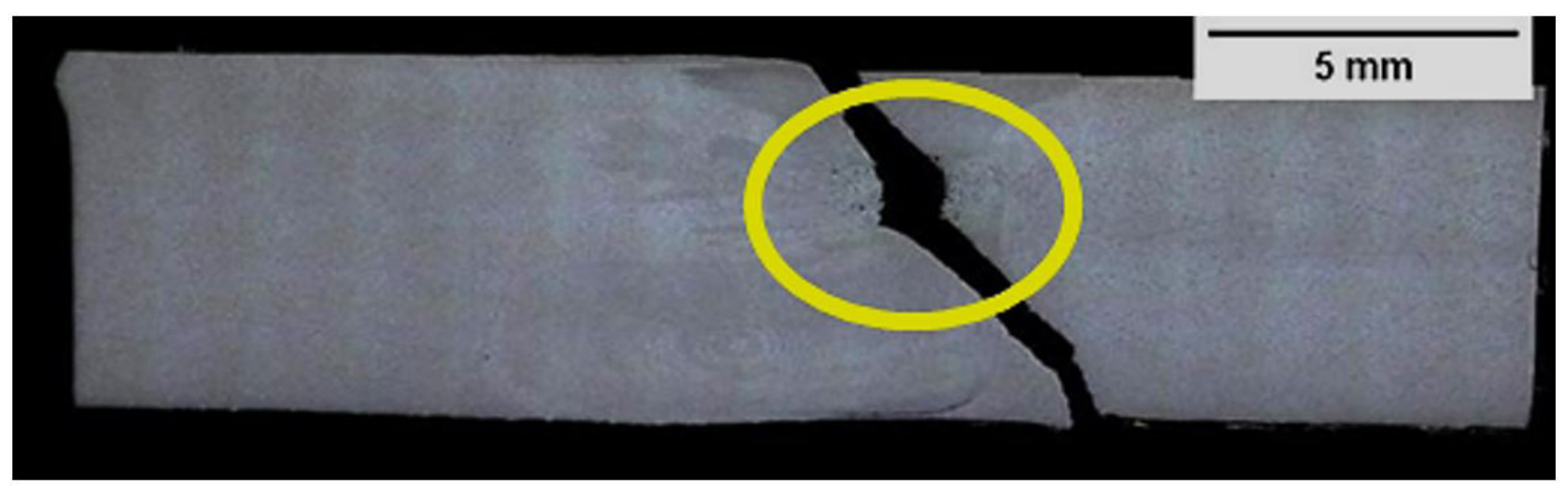

Figure 6. Macrograph showing the rupture after the tensile test in joint \#13.

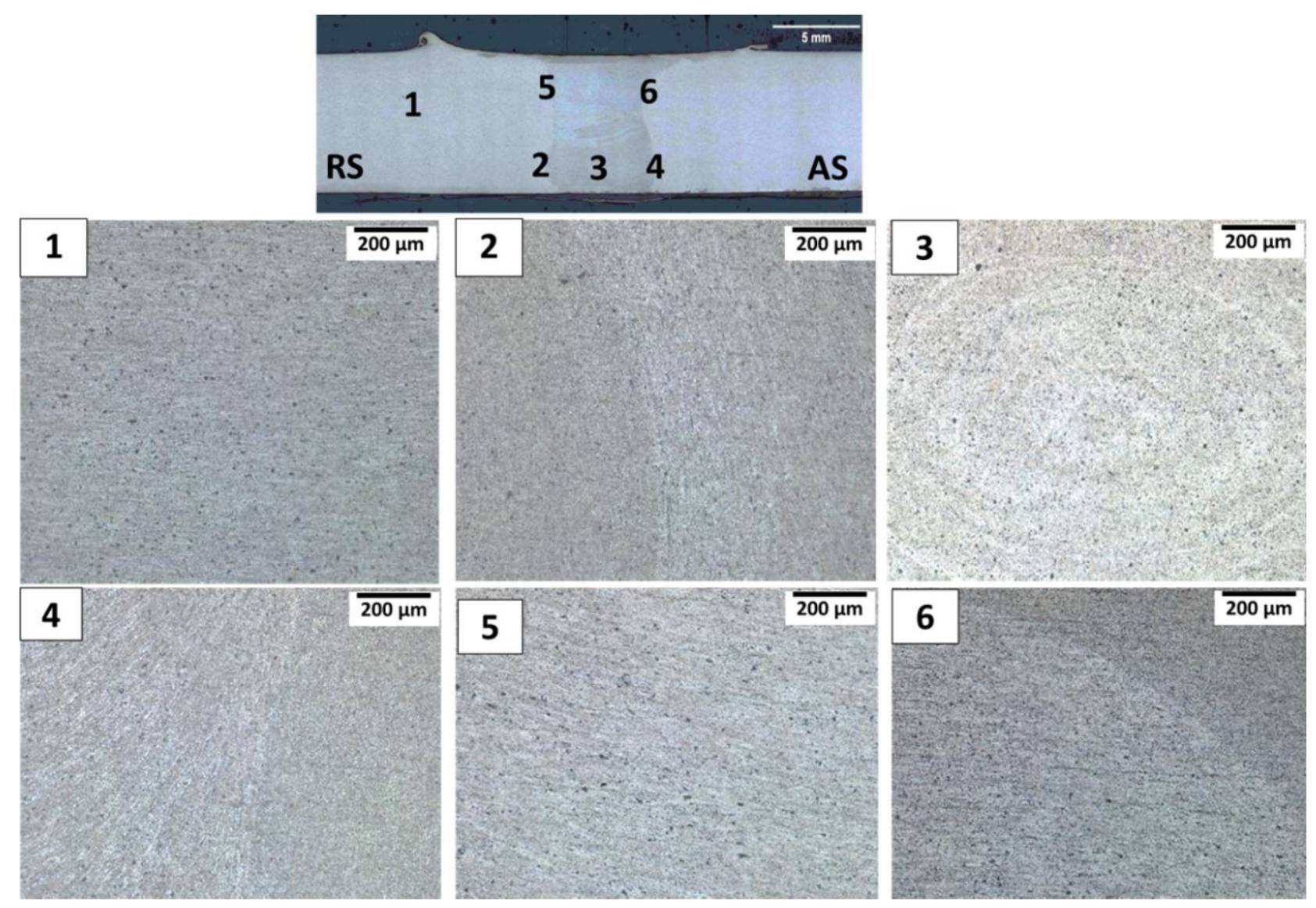

Figure 7. Joint \#13: Micrographs, according to the numbering system.

the microstructure, it was not observed a clear HAZ, which is likely to be related to the AA 5083 alloy characteristic (annealed condition) and the lower heat input promoted by FSW process. Moreover, it was observed an SPD of the material as well as a large number of precipitates. The interface between the SZ and AS is noticed to have a more heterogeneous microstructure when compared to that of the retreating side.

In Figure 8, the microhardness profiles of the weld $\# 13$ show no large differences along the distinct zones. The microhardness values ranged from 65 to $85 \mathrm{HV}$. Besides, the measurements at distinct positions $(2.1$ and $4.2 \mathrm{~mm}$ from the weld surface) did not show substantial variations in the microhardness. Therefore, the microhardness outcomes are consistent with tensile testing results, where the weld zone achieved values similar to that of the base material.

For aluminum alloys in the annealed condition $(\mathrm{O})$ and not hardenable by heat treatment, some authors also have observed that the microhardness values in varied zones of the weld were similar to the base material. Moreover, there 


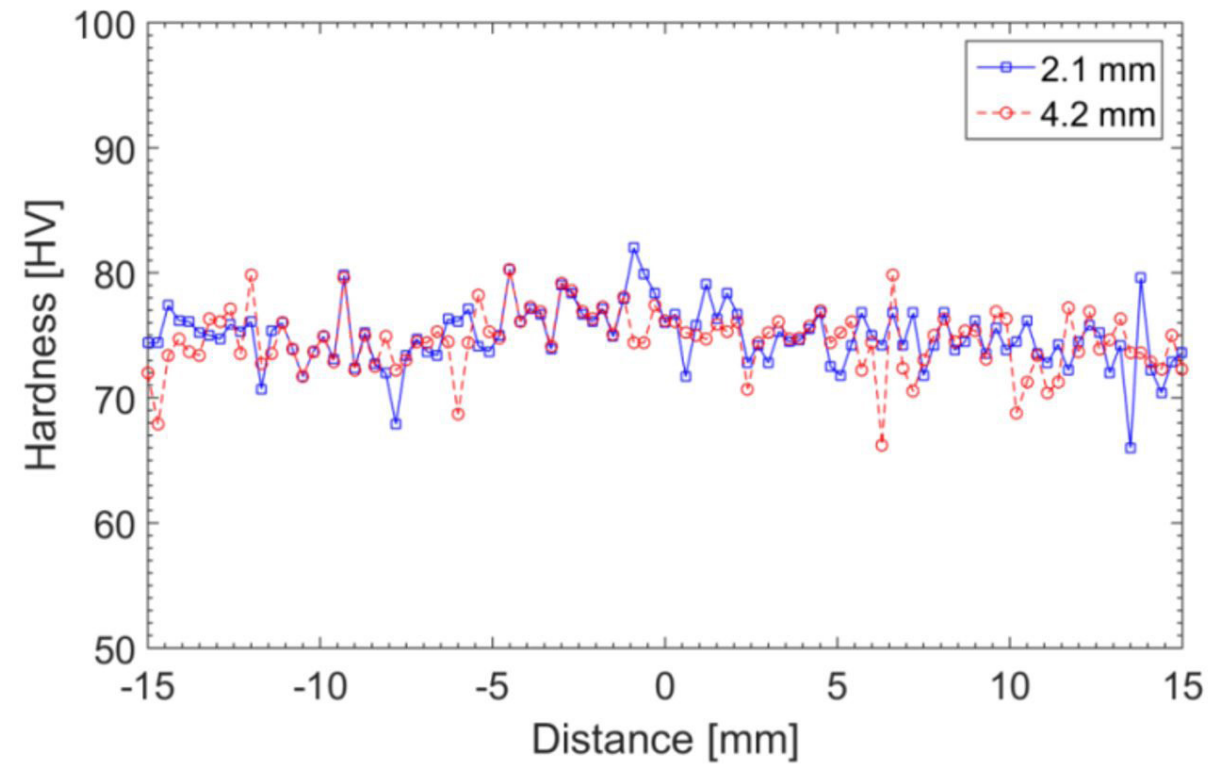

Figure 8. Microhardness profiles in joint \#13 (at $2.1 \mathrm{~mm}$ and $4.2 \mathrm{~mm}$ from the top surface).
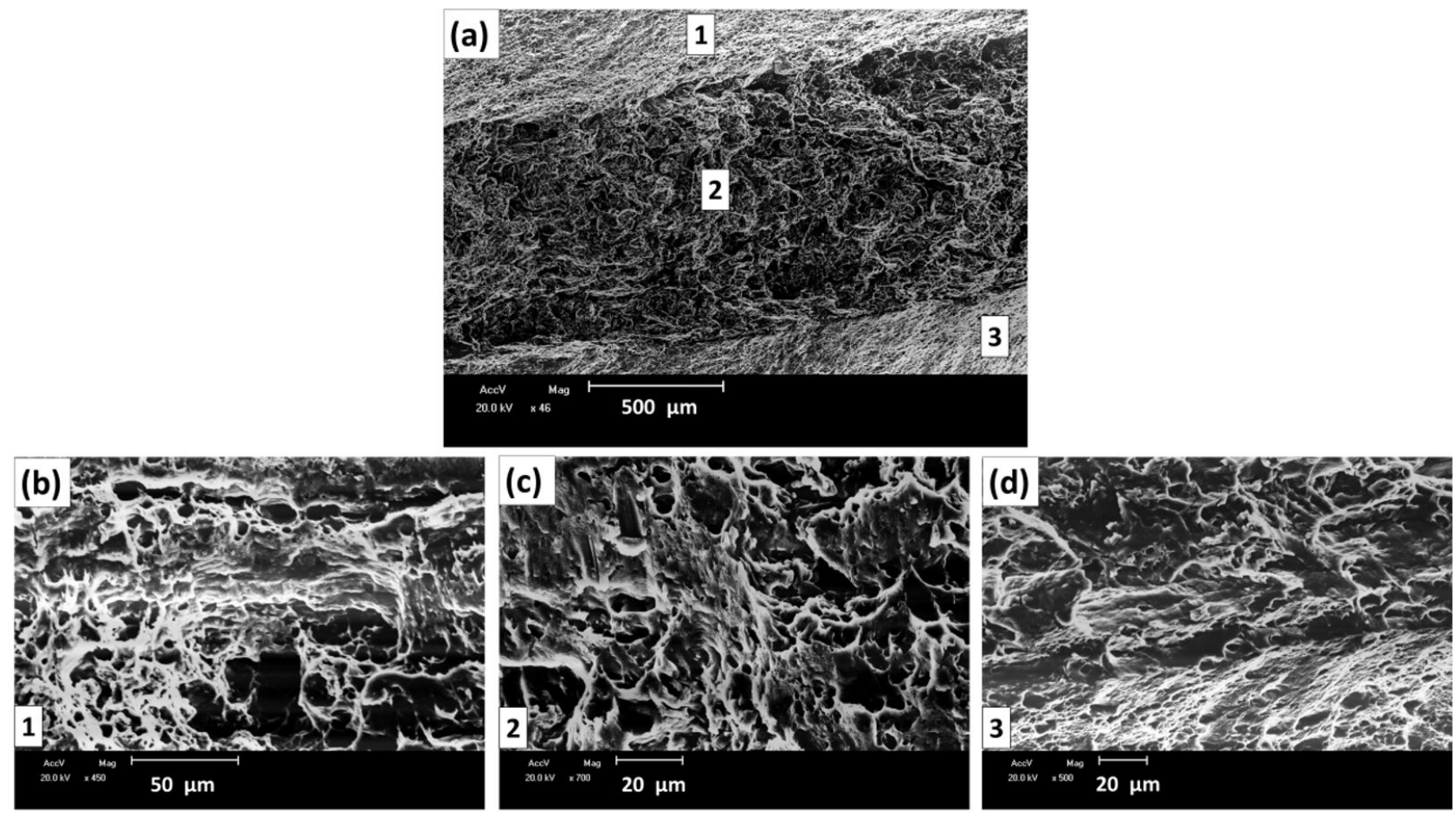

Figure 9. Joint \#13: SEM of fracture surface after tensile test (a) overview, (b) dimples (region 1), (c) deformed grains (region 2), and (d) elongated dimples (region 3).

will not be a large HAZ [27] as it usually occurs in fusion welding. In some cases, the SZ may achieve an increased microhardness due to small-sized grains [28].

\subsection{Scanning electron microscopy analysis}

A macrograph showing the rupture in tensile testing is displayed in Figure 6. Thus, this zone was observed to be similar in all the tensile test specimens, and it seems to be the same as the void defect location. Furthermore, characteristics of the best joint (weld \#13) can be seen by SEM images.

In Figure 9, the fracture surface shows grains deformed as well as elongated dimples due to the SPD process. Also, this region has some voids formed due to the failure of the coarse second-phase particles by cracking. Coalescence of voids occurred by the formation of void 
sheets and is intensified by the local strain between the expanding or growing void [expanding or growing void [28]. This mechanism occurs in ductile materials in which the voids are nucleated due to precipitates debonding [30]. In the AA 5083 alloy, the precipitates may not have a considerable influence on strength, but as a result of their intrinsic brittleness, the cracks and fractures tend to occur through these particles mainly when the material is deformed, which occurs in FSW [20]. Darras et al. [31] revealed that void growth was sensitive to strain rate so that a high strain rate decreases the interval of void coalescence.

\section{Conclusions}

FSW was successfully applied to AA5083-O aluminum alloy plates. The results of the present work can be understood as follows:

- From the matrix proposed, the best parameters chosen were tool rotational speed of $1100 \mathrm{rpm}$, transverse speed of $30 \mathrm{~mm} / \mathrm{min}$, and shoulder penetration of $0.20 \mathrm{~mm}$;

- By the top surface appearance and macrographs, it was noted that the sharp flash was preferentially formed on the retreating side, while the void defect was verified on the advancing side;

- A shoulder penetration of $0.20 \mathrm{~mm}$ plays an important role in the quality of the welds;

- The tensile testing presented satisfactory results. As an average, the YS of the joints was around $85 \%$ of the base material. Also, it was observed that the tensile test samples fractured on the advancing side. Still, the predominant fracture mode was ductile, and it occurred through void coalescence, which was probably related to the second phase precipitates;

- The microhardness profiles have not changed so much along the measurements;

- The metallography showed a defect-free joint (weld \#13). Besides, there were precipitates along the weld region.

\section{Acknowledgements}

The authors would like to acknowledge the financial support of CAPES and CNPq. Also, we would like to thank Bruning Tecnometal for the cooperation.

\section{References}

1 Associação Brasileira de Alumínio. Anuário estatístico ABAL 2016. São Paulo: ABAL; 2017 [cited 2020 Aug 14 ]. Available at: http://abal.org.br/publicacao/anuario-estatistico-abal-2016

2 Tronci A, McKenzie R, Leal RM, Rodrigues DM. Microstructural and mechanical characterisation of 5XXX-H111 friction stir welded tailored blanks. Science and Technology of Welding and Joining. 2011;16(5):433-439.

3 ASM International. Metals handbook. 10th ed. Vol. 2: Properties and selection: nonferrous alloys and specialpurpose materials. Materials Park: ASM; 1990.

4 Thakur R, Bajwa PS. Friction stir welding of 5xxx series aluminium alloys: a literature survey. International Journal of Scientific Research in Science. 2016;2(2):1129-1131.

5 Mishra RS, Mahoney MW. Friction stir welding and processing. Denton: Springer; 2014.

6 Çam G. Friction stir welded structural materials: beyond Al-alloys. International Materials Reviews. 2011;56(1):148. http://dx.doi.org/10.1179/095066010X12777205875750.

7 Kallee S, Nicholas D, Burling P. Application of friction stir welding for the manufacture of aluminium ferries. In: Proceedings of the 4th International Forum on Aluminium Ships; 2000; New Orleans. New Orleans; 2000.

8 Hori H, Hino H. Application of friction stir welding to the car body. Journal Welding International. 2003;17(3):3741.

9 Mishra RS, Ma ZY. Fricton stir welding and processing. Materials Science and Engineering R Reports. 2005;50(12): $1-78$.

10 Li Y, Trillo EA, Murr LE. Friction stir welding of aluminum alloy. Journal of Materials Science Letters. 2000;19:4751.

11 Mishra RS, Rani P. Experimental investigation of joining of aluminum alloy 5083 by Friction Stir Welding (FSW). International Journal of Research in Engineering and Innovation. 2019;3(5):306-309.

12 Klobcar D, Kosec L, Pietras A, Smolej A. Friction stir welding of aluminium alloy 5083. Materials Technology. 2012;46:25-30. 
13 Rao D, Huber K, Heerens J, Santos JF, Huber N. Asymmetric mechanical properties and tensile behaviour prediction of aluminium alloy 5083 friction stir welding joints. Materials Science and Engineering A. 2013;565:44-50. http:// dx.doi.org/10.1016/j.msea.2012.12.014.

14 Prabha AK, Putha PK, Prasad BS. Effect of tool rotational speed on mechanical properties of aluminum alloy 5083 weldments in friction stir welding. Materials Today: Proceedings. 2018;5:18535-18543.

15 Hirata T, Oguri T, Hagino H, Tanaka T, Chung SW, Takigawa Y, et al. Influence of friction stir welding parameters on grain size and formability in 5083 aluminum alloy. Materials Science and Engineering A. 2007;457(1-2):344349.

16 Walter N, Amavisca C, Santos R, Buzzatii D, Chludzinski M, Tolotti D, et al. Estudo sobre o desgaste de ferramentas no processo de Friction Stir Welding. In: XLIII Congresso Nacional de Soldagem (CONSOLDA); 2017; Joinville. Joinville: CONSOLDA; 2017.

17 Ferreira SLC, Bruns RE, Ferreira HS, Matos GD, David JM, Brandão GD, et al. Box-Behnken design: an alternative for the optimization of analytical methods. Analytica Chimica Acta. 2007;597(2):179-186.

18 International Organization for Standardization. ISO 25239-4: friction stir welding - aluminium - part 4: specification and qualification of welding procedures. Geneva: ISO; 2011.

19 American Society for Testing and Materials. ASTM E 8: standard test methods for tension testing of metallic materials. West Conshohocken: ASTM; 2013.

20 Kim YG, Fujii H, Tsumura T, Komazaki T, Nakata K. Three defect types in friction stir welding of aluminum die casting alloy. Materials Science and Engineering. 2006;415(1-2):250-254.

21 Keivani R, Bagheri B, Sharifi F, Ketabchi M, Abbasi M. Effects of pin angle and preheating on temperature distribution during friction stir welding operation. Transactions of Nonferrous Metals Society of China. 2013;23(9):2708-2713.

22 Kah P, Rajan R, Martikainen J, Suoranta R. Investigation of weld defects in friction-stir welding and fusion welding of aluminium alloys. International Journal of Mechanical and Materials Engineering. 2015;10(1):26.

23 Crawford R, Cook GE, Strauss AM, Hartman DA, Stremler MA. Experimental defect analysis and force prediction simulation of high weld pitch friction stir welding. Science and Technology of Welding and Joining. 2013;11(6):657665.

24 Leal R, Loureiro A. Defects formation in friction stir welding of aluminium alloys. Materials Science Forum. 2004;456:299-302.

25 Chen ZW, Pasang T, Qi Y. Shear flow and formation of Nugget zone during friction stir welding of aluminium alloy 5083-O. Materials Science and Engineering A. 2008;474(1-2):312-316.

26 Peel M, Steuwer A, Preuss M, Withers PJ. Microsructure, mechanical properties and residual stresses as a function of welding speed in aluminum AA 5083 friction stir welds. Acta Materialia. 2003;51(16):4791-4801.

27 Kumbhar NT, Dey GK. Friction stir welding of aluminium alloys. BARC Newsletter. 2011;321:11-17.

28 Sangalli G, Lemos GVB, Martinazzi D, Lessa CRL, Beskow AB, Reguly A. Towards qualification of friction stir welding to AA5083-O and AA5052-O aluminum alloys. Materials Research. 2019;22(5):e20190349.

29 Menzemer C, Srivatsan TS. The quasi-static fracture behavior of aluminum alloy 5083. Materials Letters. 1999;38(5):317-320.

30 Benzerga AA. Micromechanics of coalescence in ductile fracture. Journal of the Mechanics and Physics of Solids. 2002;50(6):1331-1362.

31 Darras BM, Abed FH, Pervaiz S, Abdu-Latif A. Analysis of damage in 5083 aluminum alloy deformed at different strain rates. Materials Science and Engineering A. 2013;568:143-149.

Received: 14 Aug. 2020

Accepted: 30 Sep. 2020 